Ana Patricia Melchor Organista

Licenciatura en Filosofía 


\section{Incontinencia e intemperancia en Aristóteles}

El hombre más poderoso es aquel que es total. mente dueño de sí mismo.

Aristóteles

\section{Introducción}

En este trabajo busco exponer brevemente lo dicho por Aristóteles - específicamente en su Ética nicomáquea-sobre la incontinencia y la intemperancia. Busco exponer, primeramente, lo que cada concepto significa y, partiendo de allí, analizar la relación que tiene la incontinencia con el conocimiento y con el bienestar del ser humano, y en qué proporción y de qué forma sería acertado ser continente para lograr o facilitar que el ser humano cumpla su fin, el cual es la felicidad. Me interesa también abordar, en función de estos temas, la concepción del placer y el lugar que tiene en la vida del ser humano, específicamente por la importancia que se le da dentro de nuestra sociedad, la cual suele colocarlo como el fin verdadero de todas nuestras actividades y nos invita a perseguirlo.

El trabajo se desarrollará en cuatro apartados. En el primero expondré un marco histórico para poder ubicar allí las ideas propuestas por Aristóteles; en el segundo, buscaré aclarar los conceptos que se manejan a lo largo del Libro vir de la Ética nicomáquea; en el tercer apartado ahondaré en el tema del placer, explicando la división que se hace de éste y las distintas formas en que se trata. En el último apartado busco señalar algunas de las actitudes características de nuestra sociedad respecto al placer y la incontinencia o intemperancia, partiendo de la perspectiva aristotélica.

\section{Razones para el trabajo de Aristóteles}

Es evidente que cualquier corriente ética nace de una reflexión sobre la moral, es decir, sobre la forma en que se rige la sociedad y los individuos que forman parte de ella. En una ciudad como la Arenas de Pericles, con tantos y tan grandes pensadores y considerando el interés que tenían 
sus ciudadanos así como su participación en la comunidad, resulta fácil comprender su preocupación por reflexionar sobre la mejor manera de actuar, lo que era más conveniente para alcanzar su ideal de felicidad. La propuesta de Aristóteles es, en realidad, una ética del sentido común que apela a la naturaleza del ser humano. Es eudemonista, es decir, nos da una serie de consejos para acercarnos a la felicidad que podrían resumirse en la idea de que el ser humano debe ejercer su naturaleza, que es la razón; de esta manera será virtuoso y esa virtud lo llevará a la felicidad. En su Ética nicomáquea, Aristóteles presenta una forma de ayudar a comprender lo que le resulta más conveniente: sacarlo del idealismo platónico y reincorporarlo al mundo real. En lo que respecta a este tema específico, podría decirse que busca dar respuesta a un fenómeno en el que la posición platónica no parece coincidir con la realidad. El libro vir de la Ética nicomáquea es principalmente la refutación del principio defendido por Sócrates -y luego por Platón-, que indica que si el hombre actúa mal es sólo por falta de conocimiento: el mal para ellos es producto de la ignorancia dado que cuando se posee el conocimiento, no se puede actuar incorrectamente.

Aristóteles nota, contra la teoría platónica, que se dan casos -y no pocos-en los que incluso siendo poseedor de un conocimiento, el hombre puede actuar mal. Se da cuenta de que la relación que se da entre el conocimiento y las acciones que plantean sus predecesores inmediatos puede ser bien la potencia o capacidad que lleva al acto o sólo una capacidad que no pasa de eso. Busca explicar por qué se da esto, bajo qué circunstancias y respecto a qué cosas un hombre puede llegar a actuar en contra de lo que le dicta su razón, voluntaria o involuntariamente. También analiza si, en el caso de aquellos que no son capaces de resistirse al placer, esto mismo podría corregirse; y, en el caso de quien elige el placer conscientemente, cómo se podría arreglar su razonamiento.

\section{Primeros conceptos, incontinencia e intemperancia}

Todos los conceptos que existen surgen ligados a la sociedad en que son engendrados, al pensamiento y costumbres en que se encuentran inmersos, por lo que resulta complejo, muchas veces imposible, encontrar un sinónimo exacto. Pero podemos encontrar aproximaciones que nos permitan trabajar con ellos. Los conceptos que se emplean en este caso son: la akrasia, que tomaremos como equivalente a la incon- 
tinencia y, su contrario, la continencia, que es denominada enkráteia. $\mathrm{El}$ «que la posee es quien "sabiendo que sus deseos son malos, su razón le impide que los siga" $»{ }^{1} \mathrm{La}$ akrasia -palabra compuesta por el prefijo griego «a-», que se traduce como «sin» $y$ «kratos», traducido como "gobierno", esto es, ausencia de gobierno, pero de gobierno sobre uno mismo- es la razón la cual no es capaz de mandar dentro del hombre, por ser arrastrada por deseos y pasiones.

La incontinencia es definida, pues, como la «carencia de dominio de sís. Es cuando no se da una relación coherente entre lo que se hace y lo que se piensa; consiste en saber qué cosa es buena y desearla, pero sin ser capaz de realizarla por motivos ajenos a la razón y relacionados con el placer. La intemperancia, por su parte, consiste en saber qué es lo correcto pero sin desearlo, así como desear el placer y seguirlo con plena conciencia e ignorar la razón o modificarla para elegir conscientemente el placer. En ambos casos se posee el conocimiento pero éste no lleva a la acción.

El intemperante es llevado por sus deseos, a los que él obedece por libre elección, pues estima que es necesario seguir siempre el placer del momento; el otro [el incontinente], por el contrario, aun sin tener esta manera de ver las cosas, sigue, no obstante, su placer. [...] Ahora bien: nosotros decimos que hay dos maneras de saber: existe el que posee la ciencia, sin, no obstante, utilizarla, y es el que la utiliza el que verdaderamente sabe. ${ }^{2}$

La diferencia radica entonces en los propósitos del sujeto que no es accesible a los otros, sino que sólo se pueden conocer sus actos. Está presente aquí la noción de conocimiento en acto y conocimiento en potencia. En ninguno de los dos casos este conocimiento se encuentra en acto: en el intemperante es ignorado aunque esté en potencia, ya que éste sabe qué es lo correcto pero decide no hacerlo; y en el incontinente está en potencia también, pero le es imposible llevarlo al acto por una falla en su voluntad. Es difícil que un ser humano se encuentre en un exceso

1 Guthrie, W.K.C., Historia de la filosofía griega vI. Introducción a Aristóteles, Traducción de Alberto Medina González, Editorial Gredos, S.A, España, 1981, p. 379.

2 Aristóteles, «Libro vi» en Obras completas, Ética nicomáquea, (pp. 1250 1267), Traducción de Francisco de D. Samaranch, Aguilar S. A. Ediciones, España, 1973,p. 1253. 
tal que sólo se deje llevar por los placeres en todos los sentidos y en todo momento. Las personas que no tienen dominio de sí mismos o son intemperantes o lo son sólo sobre ciertas cosas.

La causa, nos dice Aristóteles, de que no le sea posible al incontinente resistir los placeres que su razón clasifica como malos es que, aunque posee el conocimiento, se encuentra en un estado de embelesamiento.

Pues la ira, los deseos amorosos y algunas otras afecciones de este tipo producen también, de manera manifiesta, un cambio en el estado corporal e incluso provocan en algunos una verdadera enajenación [...] los que no tienen dominio sobre sí mismos están en este estado. ${ }^{3}$

Este estado de enajenación que el incontinente tiene frente a los placeres impide que su razón tenga una relación coherente con su comportamiento; es un impedimento para actuar acertadamente.

Podemos observar que alguien posee un conocimiento y actúa guiado por el placer, pero no parece que sea fácil definir si se trata de alguien incontinente o de alguien intemperante, es decir, si actúa porque no es capaz de resistir el placer o si lo hace porque decide ignorar su razón, pero es necesario identificar de qué caso se trata para poder corregirlo o, al menos, para plantear algún camino a seguir buscando mejorarlo. Hay un aspecto muy importante que nos permite diferenciar al intemperante del incontinente: la capacidad de sentir remordimiento. El intemperante no siente remordimiento, pues ha decidido ignorar la razón, mientras que el incontinente sí siente remordimiento, pues hace lo que considera incorrecto por falta de autodominio.

Aristóteles considera que ambos casos, tanto la incontinencia como la intemperancia, son lamentables y deberíamos ser capaces de eliminarlos, pues somos seres racionales y lo más conveniente para nosotros es guiarnos por esa razón. Tal reflexión lleva a dos conclusiones distintas e incluso contradictorias sobre cuál de los dos vicios es más sencillo de tratar. La primera conclusión es que el intemperante es más fácil de corregir que el incontinente, pues el primero se guía por una razón $y$, aunque se trate de una razón equivocada, hay una coincidencia entre lo que se piensa y lo que se hace; mientras que el incontinente no se guía por ninguna razón, porque no es capaz de ello. La segunda reflexión concluye en que el incontinente es más difi-

\footnotetext{
3 Ibidem., p. 1254.
} 
cil de corregir que el intemperante, pues el principio de la razón en el intemperante está corrompido y cambiar eso es muy difícil ya que ni siquiera siente remordimiento. $Y$ pareciera que en el caso del incontinente el principio se encuentra intacto y el trabajo consiste en hacer que la voluntad se fortalezca.

Resulta interesante su aparente contradicción, pero encuentro que de ambas conclusiones podemos extraer lo que es necesario para corregir los dos casos. En el caso del incontinente será necesario fortalecer su voluntad. Aristóteles nos ha dicho que la virtud sólo se puede adquirir con el hábito, esto es, que practicando actos virtuosos lograremos ser virtuosos. Parece que podemos decir lo mismo de la voluntad: sólo se puede tener voluntad si se pone en práctica. En el caso del intemperante será necesario regresar su razón al curso que tendría naturalmente, en el cual es evidente que el placer no es un fin en sí mismo. Sólo los argumentos racionales pueden cambiar realmente las concepciones de alguien, pero parece que este tipo de personas han decidido ignorar esos argumentos y crear los propios.

\section{La concepción del placer}

La postura de las personas respecto al placer suele ser radical: lo presentan como absolutamente bueno y deseable, o absolutamente malo y repudiable. Aristóteles propone un balance entre ambas posturas y los resultados de sus reflexiones son un punto medio donde la razón y el cuerpo son tomados en cuenta. En éste tiene mayor peso la primera postura, pero la segunda no es dejada de lado. Estas posturas ya se encontraban presentes en algunas de las grandes escuelas del pensamiento griego, una presentaba al placer como el fin último del ser humano - la de Eudoxo- y otra como algo reprobable que debe evitarse a toda costa -la de Espeusipo-, pero Aristóteles no se inclina por ningún extremo, sino que les otorga la importancia que tienen dentro de la vida de los seres humanos sin darles un lugar privilegiado, el cual está reservado a la razón. Él sabe que se trata de algo natural y que si se busca en exceso se actúa irracionalmente. Esto había sido planteado ya por los filósofos presocráticos: "Si se excede la medida, lo más placentero se convierte en lo más carente de placer" ${ }^{4}$

4 Demócrito según Estobeo, Los filósofos presocráticos, vol. III, Traducción de Luis Cordero, Biblioteca Clásica Gredos, España, 1986, p. 375. 
Es respecto al placer que se es incontinente o intemperante, pero el placer no es el mismo siempre. Aristóteles divide los placeres en dos clases: el primero se caracteriza por eliminar el dolor; estos placeres son violentos y pueden volver a los hombres intemperantes o incontinentes. Los placeres de la segunda clase son buenos por sí mismos y no dañan al hombre.

Admitamos, pues, que entre los deseos y los placeres pertenecen unos a la categoría de las cosas bellas, honestas y deseables; entre los placeres, en efecto, unos son naturalmente deseables, otros son intermedios, según la distinción establecida anteriormente; por ejemplo, los bienes materiales, las ventajas pecuniarias, la victoria y los honores [...]. No hay ninguna perversidad en estos sentimientos, [...] sin embargo, el exceso es aquí reprobable $y$ se debe evitar. ${ }^{5}$

Los placeres con los que debemos tener cuidado son los físicos, los que van dirigidos a eliminar el dolor. Estos placeres son comunes a todos y muchas veces cuando hablamos de placer, pensamos que sólo existen los de esa clase.

No todos siguen el mismo placer, pero sí todos, por lo menos, corren detrás de un placer. $[. .$.$] son los placeres del cuerpo los que conservan este nombre,$ de alguna manera por derecho de herencia, por el hecho de que uno se entrega a ellos muy a menudo y porque todos los hombres participan de ellos. ${ }^{6}$

La base de nuestros actos es el pensamiento, pero lo que nos impulsa a actuar es la búsqueda de placer. Pareciera que la razón no es suficiente para hacer que alguien actúe, es necesaria una motivación; algunas son necesarias y se deben buscar sólo en la medida en que lo son y no caer en un exceso irracional. Las cosas que nos producen placer no lo hacen siempre o, al menos, no en el mismo nivel, esto se debe a la complejidad de nuestra naturaleza. Quien busca placeres vergonzosos o quien los busca en exceso hace mal, pues va en contra de su razón. El placer, entonces, puede convertirse en un obstáculo de la razón, puede incluso intercambiar papeles con ella y tomar las riendas de los actos humanos. Esto es lo que sucede en los que carecen de domiñio de sí.

s. Op. cit., p. 1255.

6 Ibidem., p. 1265. 
Lo más deseable sería que la razón fuera el principio de acción de todos nuestros actos y que éstos fueran elegidos en función de su beneficio en general, no únicamente en el placer que producen. Pero no es posible separar el placer ni su búsqueda de nuestras acciones ni de nosotros mismos, pues tiene un papel importante en nuestras vidas -necesario, incluso- que mientras esté guiado por la razón no será dañino. El placer, pues, no debería ser un impedimento para el ejercicio de la razón, es común a todos y parte fundamental de nuestros actos. El ser humano necesita de los placeres para ser feliz, pero el placer en exceso lo vuelve infeliz y esto es evidentemente irracional. Para Aristóteles, el fin supremo del hombre es la felicidad, y el placer -o aquello a lo que acostumbramos llamar placer- es un medio para alcanzar un fin (evitar el dolor) y no un fin en sí mismo, no puede ser la meta última, porque no es completo. El placer puede convertirse en un obstáculo para la verdadera felicidad si se deja de lado a la razón.

\section{Las soluciones de Aristóteles}

Si aplicamos estas conclusiones aristotélicas a nuestra sociedad actual nos encontraremos con que primeramente debemos definir si la mayor parte de los individuos es intemperante o es incontinente. Si buscamos entender por completo los propósitos de un sujeto nos encontraríamos en graves problemas y seguramente no llegaríamos a una conclusión, pero si partimos del presupuesto de que es posible diferenciar la incontinencia de la intemperancia por el hecho de sentir remordimiento, podría parecer que actualmente abundan personas intemperantes que no muestran ningún remordimiento por buscar el placer sobre todas las cosas, y también observamos muchos casos de personas que siguen su placer y atribuyen eso a su falta de voluntad. Se presentan ambos casos y en cada situación se deberá analizar particularmente a la persona. El resultado parece, sin embargo, ser el mismo: personas que no son racionales, que no se detienen a reflexionar sobre sus actos y que no logran que lo que creen sea racional y que esas creencias se reflejen en sus actos.

Si observamos ya no a los individuos y nos concentramos en los mensajes de los medios, nos encontramos con una realidad abrumadora: es casi como si en lugar de ayudar al ser humano a forjar una 
voluntad y hacer que su razón sea quien dirija su comportamiento, se buscara estimularlo de tal forma que aunque su razón le indique que algo es incorrecto, sea incapaz de contenerse de realizarlo por la fuerza de su deseo. En la actualidad son pocos los que logran ser racionales aunque todos somos capaces de serlo. Es más sencillo dejarse llevar por lo que alguien más dice que forjarse una opinión propia y ser coherentes con ella. Pero somos seres racionales y ejercer esa racionalidad es el mejor camino a seguir en pos de nuestro bienestar e, incluso, nuestra felicidad. Es cierto que buscamos el placer y huimos del dolor, pero dejarnos llevar por esto nos hace ignorar lo que realmente nos constituye como seres humanos, que es esa reflexión, esa racionalidad y esa capacidad de hacer lo que consideramos correcto.

Ahora bien, por lo dicho parece que en estos tiempos no tenemos una referencia clara sobre lo que es el bien, sobre cuál es nuestro fin en el mundo. Habrá quien responda que su fin es la felicidad, pero este concepto es ahora más equívoco que unívoco, de forma que decir «felicidad» actualmente no nos saca de dudas. No obstante, considero que estos conceptos se encuentran más cercanos al ejercicio de nuestra razón que a la persecución irracional del placer. La propuesta general que nos hace Aristóteles es que el hombre será feliz si ejerce su naturaleza racional. Y ni el incontinente ni el intemperante hacen eso. De nada nos sirve ser racionales si no somos capaces de actuar conforme a razón. 